\title{
The role of eye dominance in recalling lexical items in second language acquisition
}

Shakouri, Nima $\bowtie$

Department of English, Science and Research Branch, Islamic Azad University, Tehran, Iran (shakouri.ni@gmail.com)

Maftoon, Parviz

Department of English, Science and Research Branch, Islamic Azad University, Tehran, Iran (maftoonp@gmail.com)

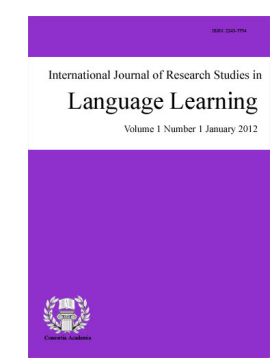

ISSN: $2243-7754$ Online ISSN: 2243-7762

OPEN ACCESS

\section{Abstract}

The purpose of the study was to investigate whether participants' eye dominance can be an indicator of success in recalling lexical items in second language acquisition (SLA). In this regard, the present researchers selected 30 participants from a relatively popular English language center, Iranian Language Center located in Bandare-e Anzali, Iran. The participants were also homogenized on their language proficiency level using the Babel English Language Placement test. They were found to be at intermediate level of language proficiency. By means of a convergence near-point test, the researchers selected the participants who were right-and left-eyed dominants. The results of independent samples $t$-test indicated that eye laterality is not a valid indicator of participants' success in recalling L2 lexical items.

Keywords: eye dominance; eye movement; eye preference; laterality; lexical items 


\section{The role of eye dominance in recalling lexical items in second language acquisition}

\section{Introduction}

The brain is a complex circuitry system. It is circuitry because it is connected to everything in the body. The new theories in the 1970s about the hemispheres of the brain that caused scientists to term people as left- brained or right-brained was no longer used (Saunders \& Vawdrey, 2002). According to Slegers (1997), children are born with equal sides of the brain. Both sides of the brain can work independently and can work together. Nevertheless, as Slegers states, the right side develops first and grows faster. This is the side of the brain that deals with emotions. The left side of the brain starts to grow later and is in charge of new learning. Moreover, the right hemisphere or the non-language hemisphere is responsible for comprehension. Along the same vein, Sperry (1981) contends, "lateralized testing for linguistic abilities showed the right hemisphere to be largely mute and agraphic, but nevertheless able to comprehend" (p. 2). Besides, although research shows that the left hemisphere is often described as verbal and the right as perceptual, it is inconclusive and does not hold up as a generalization (Kosslyn \& Miller, 2014).

Working on the brain, per se, may not be ethically justified, but eyes, hands, and other paired organs have potentials to map the directions of learning L2 in the brain. Given the scarcity of eye movement studies in bilingual language processing, the purpose of the present study is to record eye movements of bilinguals reading L2 lexical items in order to investigate whether eye dominance has the potential to become an indicator of success in SLA or not.

\section{Review of related literature}

The interest of eyedness traces back to the end of the $16^{\text {th }}$ century. Two concepts related to eyedness are eye preference and eye dominance. Eye preference, as to McManus (2002), is a sensorimotor asymmetry seen in all bilateral anatomical pairs such as ears, nostril, and hands. Eye dominance, in contrast, refers to the eye for which a stimulus is predominantly reported when two rivaling stimuli are presented through a stereoscope (Mapp, Ono, \& Barbeito, 2003). Although the terms are usually used interchangeably, "eye dominance is a much less consistent trait than eye preference" (Fagard, Monzalvo-Lopez, \& Mamassian, 2008). Fagard et al. go on to hold that there seems no relationship between eye preference and eye dominance.

Although the human anatomy is symmetrically arranged about a central vertical axis, most people use one side of their body with greater frequency, facility, or skill than the other (Pointer, 2012). In terms of the laterality differences of the visual system, the term implies that one part of the visual system contributes more to the final perception than another part. Although several studies (e.g., Porac \& Coren, 1975) argue that eye dominance is a fixed trait, eye dominance does appear to change depending upon direction of the gaze (Porac \& Coren, 1975), due to image size changes on the retinas (Banks, Ghose, \& Hillis, 2004). Mapp et al. (2003) contend that eye dominance depends on variables such as size and color of the stimulus (Mapp et al., 2003). As Porac and Coren (1975) hold, eye dominance is a fixed phenomenon. However, to several scholars (e.g. Khan \& Crawford, 2003), eye dominance switches from one eye to the other in horizontal eye position.

In this regard, Woodhouse (2009) outlines three types of dominance: sighting dominance, sensory dominance, and acuity dominance. Sighting dominance is most easily measurable. An experimenter needs only to ask an observer to peer through a pinhole to determine sighting dominance, or the subject fixates an object that is moved toward the nose until divergence of one eye occurs. In sensory dominance, in contrast, the eye that produces the longer-lasting monocular image is considered to be dominant. Finally, the third type of dominance, acuity dominance, refers to the status that the eye with the higher acuity is considered to be dominant and can be measured using standard acuity tests. As Coren and Kaplan (1973) show, this form of dominance is invoked in 
The role of eye dominance in recalling lexical items in second language acquisition

situations in which stimuli are degraded in some way, such as being difficult to resolve or very briefly flashed. Porac and Coren (1975) assert that the concept of acuity dominance can also be extended to conditions in which clarity of vision in one eye is markedly reduced. However, the distinction between the three types of dominance may not be as clear-cut as it appears (Woodhouse, 2009).

\subsection{Research on eye movement}

Eye movement or saccade brings the eyes from one text location to the next. The time between two saccades is the eye fixations. Besides, as to Godfroid (2012), the fixation point is divided into three regions: the fovea (the central $2^{0}$ of vision where visual acuity is best), the parafovea (which extends out to $3^{0}$ to either side of the foveal region, and the periphery. In effect, as one moves away from the center of the visual field, visual acuity decreases.

Eye movement has recently become the central area of SLA research, namely explicit and implicit processing (Godfroid \& Winke, 2015). As Godfroid and Winke state, research on eye movement provides fined-grained information regarding the time course of processing and contributes to the study of implicit and explicit processes. Studies conducted by Siyanova-Chanturia, Conklin, and Schmitt (cited in Godfroid, 2012) have compared native and nonnative speakers' fixation times for figuratively used idioms (e.g. 'ring a bell' = sound familiar), literally used idioms (e.g. 'ring a bell' = sound a small metal object), and matched novel phrases. Their analyses revealed that the well-known processing advantage for idioms in the L1 did not hold in the L2, with nonnative speakers actually taking longer to read figuratively used idioms than literally used ones. Schmidt (1995) also considers eye tracking methodology as a means to measure learners' noticing of new forms in written L2.

The majority of studies on hemisphere influences on vision have used recall of tachistoscopically-presented words as the dependent variable (Banich, 2003). Research shows that while English words presented briefly in left and right visual field to English speaking individuals shows greater recall accuracy in the right visual field. In a sense, although eye tracking is still a novel methodological procedure in SLA, the current work based on brain laterality attempts to investigate whether eye dominance is a valid indicator of recalling lexical items in L2 or not.

\subsection{On the notion of laterality}

Herrmann (1999) asserts "the human body is made up largely of [internal and external] paired structures, most of which are not perfectly matched" (p. 2). This asymmetry in the human body results in the concept of dominance. Stated differently, one might have a dominant external member including eyes, legs, and hands. According to Herrmann, most of these types of dominance are made early in life and gradually they get strengthened. Internally located members include lungs, kidneys, hemispheres, and limbic systems. The structures (i.e., two hemispheres and two limbic systems) in the brain are connected together by a powerful link called hippocampus. Like external pairs of the human body, the internal pairs are asymmetrical. As to Hermann, the pairs are physically and chemically different because they are specialized for different functions. Herrmann holds that the more frequent we use a member (e.g., a hand), the more competent it becomes. Similarly, when one wants to cope with a complex task, two hands are in coalition, and therefore the internal structures are no exception. Hermann claims that at birth no dominance exists between the hemispheres of the brain, and the brain is essentially whole. Indeed, preferences are the result of maturity.

Field (2004) defines brain laterality as "the view that one of the hemispheres of the brain has or develops a special responsibility for language" (p. 46). It is worth mentioning that left and right hemispheres are not exactly mirror images of each other in terms of functions. In fact, as Cowles (2011) declares, "many higher-level cognitive functions are lateralized, meaning that parts of the right hemisphere and left hemisphere specialize and take on functions that the other hemisphere does not " (p. 94). For the most part, the brain is organized such that the left part of body is controlled by the right hemisphere, and the information coming from the right part of body is controlled by the left hemisphere. Nevertheless, in terms of language, the issue is a bit different, left-handers, though highly dominated by right hemispheres, have dominance in the left hemisphere. Likewise, in right-handers, 
the right hemisphere also plays a role in language ability, although exactly what this role is and how it works is still something a mystery (Cowles, 2011). Nevertheless, left-hemisphere dominance for language has proven to be one of the most robust findings in the lateralization literature (Gazzaniga, LeDoux, \& Wilson, 2002).

Along the same vein, right hemisphere involvement, as Bottini et al. (1994, cited in Mason \& Just, 2006) hold, during narrative processing has been noted in several neuroimaging studies, both for comprehension and production. In fact, right hemisphere may reflect coherence at the discourse level. Research shows that patients with right-hemisphere damage have difficulty connecting and interrogating semantically distinct concepts (Beeman, 1993).

Regarding the mentioned review of literature, the following research questions were raised:

$>\quad$ Is there any statistically significant difference between the left- and right-eyed dominant participants in recalling 12 lexical items presented to the left visual field?

$>\quad$ Is there any statistically significant difference between the left- and right-eyed dominant participants in recalling 12 lexical items presented to the right visual field?

Based on the research questions, the following research hypotheses were proposed:

$>\quad$ There is no significant difference between the left- and right-eyed dominant participants in recalling 12 lexical items presented to the left visual field.

$>$ There is no significant difference between the left- and right-eyed dominant participants in recalling 12 lexical items presented to the right visual field.

\section{Methods}

\subsection{Participants}

The participants participating in the present study were 30 Iranian EFL learners (15 males and 15 females) who were randomly selected from 120 language learners studying at a relatively popular English language center (i.e., Iranian Language Center) in Guilan, Iran. The participants were also homogenized on their language proficiency level using the Babel English Language Placement test. They were found to be at intermediate level of language proficiency. It follows that the participants had announced their written consent to participate in the experiment. The rationale behind this selection was to exclude those students whose English was far better or worse than the norm of the classes. This enables the present researchers to conclude that language proficiency had no possible effect on the result of the study.

\subsection{Instrumentations}

Three instruments are employed in the present study:

Babel English Placement test - The first instrument used in the study was the Babel English Language Placement test employed to measure the general language proficiency level of the participants and to ensure that they all belonged to the same population. The Babel English Language Placement test consists of four sections of 25 reading, grammar, and lexical items. Multiple choice format is regarded as the format for this test in order to ensure swift marking. This format includes those items which measure the recognition of true responses to reading, grammatical, and lexical sections. Also, this test can accurately report the general language proficiency of the learners (Maftoon \& Rezaie, 2013).

Lateralizer software - To measure participants' reaction time when the stimulus (here lexical item) presented to the left or right visual field, the researcher used a lateralizer software. The software was designed based on the 
The role of eye dominance in recalling lexical items in second language acquisition

divided visual field (DVF) paradigm such that the stimuli (e.g., lexical items) are tachistoscopically presented on the monitor of the computer. "Divided visual field technique is one of the earliest and most used methods for studying asymmetry in normal subjects" (Alves, Fukusima, \& Aznar-Casanova, 2008). It was introduced by Mishkin and Forgays (1952) and involves the tachistoscopic presentation of visual stimuli in the periphery of the visual field.

Macintosh computer monitor - The lateralizer software was installed in a Macintosh computer.

Convergence near-point test - It is an objective test of ocular dominance. The participant fixates an object that is moved toward his/her nose until divergence of one eye happens. The Convergence near-point test, as reported by Rice, Leske, Smestad, and Holmes (2008), has almost perfect test-retest reliability $(\mathrm{k}=0.84)$.

\subsection{Procedure}

The pretest phase of the study took place two weeks before the experiment. During the pretest, participants were given the Babel English Language Placement test to investigate the homogeneity of the participants. To determine the participants' eye dominance, the present researchers used the Convergence near-point test. The participants, individually, took a ruler and attach a piece of paper to it in which a letter has been written in $1 / 16^{\text {th }}$ of an inch height and width. The participants needed to move the ruler towards their eyes in a straight line with two hands until the letter in one of the eyes became blur; that eye was considered as the non-dominant eye. In case, the ruler stopped by the participant's nose and the picture did not become blur, then neither of the eyes was dominant. In so doing, the exam room was empty of any auditory object or stimuli. Later on, each participant was requested to sit in front of a computer screen at a distance of $50 \mathrm{~cm}$. In the same line, there were presented 6 known words. The words were randomly presented to the left and right visual fields of a computer screen. Together with the known words, six unknown words were also presented to the left and right visual fields of the computer screen. The lexical items were presented laterally between $2.5^{\circ}$ and $3^{\circ}$ degrees from the fixation point. The fixation point was inserted in the center of the visual field. Since the fixation point might be difficult to maintain, the lexical items were presented briefly (i.e., $180 \mathrm{~ms}$ ) to preclude any eye movements off fixation (Fischer \& Weber, 1993). Further, to measure the participants' reaction time, they were requested to push the $\mathrm{H}$ button of the keyboard for the known words appeared in the left visual field and the G button of the keyboard for the known words presented to the right visual field. The researchers measured the reaction time for recalling the given word presented to the left or the right visual field. It is worth mentioning that the subjects were unaware that the examiner was recording the reaction time of recalling the words.

\section{Results and discussion}

\subsection{Testing null hypothesis one}

To answer the research question contending whether there is any statistically significant difference between the left- and right-eyed dominant participants in recalling L2 lexical items that appear in left visual field, the present researchers ran an independent samples $t$-test to compare the left-dominant participants' recalling of lexical items with right-dominant participants' recalling of lexical items when the stimulus (i.e., lexical items) was presented to the left visual field. The results demonstrated that there was no significant difference in the scores of left- eyed dominant participants $(M=843, S D=169)$ and right-eyed dominant participants' scores $(M=812$, $\mathrm{SD}=210)$ conditions; $\mathrm{t}(48)=.55, p=(.58)$. These results suggest that there should be no statistically significant difference between left- and right-eyed dominant participants in recalling lexical items that appear in the left visual field. This means that right- and left-eyed dominant participants have performed similarly on the recalling of L2 lexical items in the left visual field. 
To answer the second research question asserting whether there is any significant difference between the leftand right-eyed participants in recalling L2 lexical items that appear in the right visual field, another independent samples t-test was performed. The results depicted that there was no significant difference in the scores of left-eyed dominant participants $(\mathrm{M}=848, \mathrm{SD}=210)$ and right-eyed dominant participants' scores $(\mathrm{M}=816, \mathrm{SD}=198)$ conditions; $\mathrm{t}(48)=.55, p=(.58)$. These results revealed that there was no statistically significant difference between the left-and right-eyed dominant participants in recalling L2 lexical items that appear in the right visual field this means that right- and left-eyed dominant participants have performed similarly on the recalling of L2 lexical items in the right visual field.

Although eye-movement method is a particularly useful tool for L2 acquisition researchers, either left- or right-eyed dominance is not a valid indicator for the study of individual differences in SLA. The findings of the present study is compatible with Fagard et al. (2008) who came to hold that there is no relationship between eye preference and reading proficiency. However, the present research did not ignore the findings by Galin and Ornstein (1972, cited in Zeinaly \& Ashayeri, 2000) that the movement of eye depends on the type of information processed so that verbal information processing is related to the left hemisphere. In fact, when one of the hemispheres is activated, the eyes tend to be stunning at the visual field of that hemisphere. In a sense, the findings of this study indicate that the study of look direction is an evaluated method in the study of the brain hemispheres performance. Still, eye dominance, independently, cannot be considered as a valid indicator of SLA. That is, no research findings, per se, came to conclude that left- or right-eyed participants, owning to their eye-dominance have priority in language learning. Put differently, either a person is left-eyed or right-eyed is not an advantage for him or her in learning a second language. In effect, eye movement is a feature dependent upon external factors, including the topics to read and facial features like color and shape.

\section{Conclusion and implications}

Lateralization, per se, occurs in the paired organs of the body, such as hands, ears, and hemispheres. As to Khabiri and Heidari (2011) "[brain laterality] can be an important issue in developing a theory of L2 acquisition" (p. 60). In fact, as children mature, various functions are lateralized to their left or right hemispheres. Henceforth, teachers investigate gender differences to be better able to enhance their effectiveness in the classroom. Besides, investigating participants' brain laterality will pave the way to determine males and females' thinking styles in order to facilitate the process of teaching lexical items efficiently. Accordingly, being aware of learners' brain dominance, the teachers can improve the efficiency of their own teaching, increase the success rate, and also advise the learners to utilize the appropriate strategies to recall and acquire L2 lexical items. In effect, knowing the functions localized to the left- or right-hemispheres provides helpful information about the most effective way of teaching vocabulary that leads to a more durable retention of L2 lexical items.

However, eye dominance, per se, is not a valid indicator of success in SLA because eye dominance does appear to change depending upon the direction of gaze and size of the retina. Unlike handedness, eye dominance does not indicate brain dominance. In the same line, Jagadama and Kutty (2012) put forth, "the eye preferred for sighting does not indicate handedness" (p. 19). As to them, it is not surprising to claim that "each eye projects to both cerebral hemispheres whereas each hand is represented mainly in the opposite hemisphere" (p. 19). In fact, "the lateralization of eye function is the result of the development of binocular vision, with overlapping of the visual fields of the two eyes" (Jagadama \& Kutty, 2012, p. 23). Nevertheless, the present study is at variance with Hannaford (2003, cited in Viskari, 2005) who contends that a person whose dominant eye is on the opposite side to his/her dominant hemisphere is able to process information at full capacity. On the other hand, a person whose dominant eye is on the same side as his/her dominant hemisphere processes information below capacity. Nevertheless, what the study came to conclude is that the dominance of the eyes does not play a critical role in recalling L2 lexical items. More importantly, the factors involved in eye movement are not owning to the dominance of eyes, but to the color, size, and the type of information to be processed. 


\section{References}

Alves, N. T., Fukusima, S. S., \& Aznar-Casanova, J. A. (2008). Models of brain asymmetry in emotional processing. Psychology and Neuroscience, 1(1), 63-66. http://dx.doi.org/10.3922/j.psns.2008.1.010

Banich, M. T. (2003). The divided visual technique in laterality and interhemesipheric integration. In K. Hugdahl (Ed.), Experimental methods in neuropsychology (pp. 47-64). New York: Springer Science+Business Media, LLC.

Banks, M. S., Ghose, T., \& Hillis, J. M. (2004). Relative image size, not eye position, determines eye dominance switches. Vision Research, 44(3), 229-234. http://dx.doi.org/10.1016/j.visres.2003.09.029

Beeman, M. (1993). Semantic processing in the right hemisphere may contribute to drawing inferences during comprehension. Brain and Language, 44, 80-120. http://dx.doi.org/10.1006/brln.1993.1006

Coren, S., \& Kaplan, C. P. (1973). Patterns of ocular dominance. American Journal of Optometry and Archives of American Academy of Optometry, 50, 283-292. http://dx.doi.org/10.1097/00006324-197304000-00002

Cowles, H. W. (2011). Psycholinguistics. New York: Springer Publishing Company.

Fagard, J., Monzalvo-Lopez, K., \& Mamassian, P. (2008). Relationship between eye preference and binocular rivalry and between eye-hand preference and reading ability in children. Developmental Psychobiology, 50(8), 789-798. http://dx.doi.org/10.1002/dev.20328

Field, J. (2004). Psycholinguistics: The key concepts. London: Routledge.

Fischer, B., \& Weber, H. (1993). Express saccades and visual attention. Behavioral and Brain Sciences, 16, 553-567. http://dx.doi.org/10.1017/S0140525X00031575

Godfroid, A. (2012). Eye tracking. In P. Robinson (Ed.), The Routledge encyclopedia of second language acquisition (pp. 234-236). New York: Routledge.

Godfroid, A., \& Winke, P. (2015). Investigating implicit and explicit processing using L2 learners' eye-movement data. In P. Rebuschat (Ed.), Implicit and explicit learning of languages (pp. 325-348). Amsterdam: John Benjamins. http://dx.doi.org/10.1075/sibil.48.14god

Herrmann, N. (1999). The theory behind the HBDI and whole brain technology. Retrieved from http://www.hbdi.com/Home/?directory=100024_articles\&actualFile=100543.pdf

Jagadama, A., \& Kutty, K. (2012). Effect of ocular dominance on the latency and amplitude of visual evoked potentials. IOSR Journal of Dental and Medical Science, 2(4), 19-24. http://dx.doi.org/10.9790/0853-0241924

Khan, A. Z., \& Crawford, J. D. (2003). Coordinating one hand with two eyes: optimizing for field of view in a pointing task. Vision Research, 43, 409-417. http://dx.doi.org/10.1016/S0042-6989(02)00569-2

Kosslyn, S., \& Miller, W. (2014). Left brain, right brain: Two sides, always working together. Retrieved from https://www.psychologytoday.com/blog/the-theory-cognitive-modes/201405/left-brain-right-brain-twosides-always-working-together

Maftoon, P., \& Rezaei, G. (2013). Cognitive style, awareness, and learners' intake and production of grammatical structures. Journal of Language and Translation, 3(3), 1-5.

Mapp, A. P., Ono, H., \& Barbeito, R. (2003). What does the dominant eye dominate? A brief and somewhat contentious review. Perception \& Psychophysics, 65(2), 310-317. http://dx.doi.org/10.3758/BF03194802

Mason, R. A., \& Just, M. A. (2006). Neuroimaging contributions to the understanding of discourse processes. In M. J. Traxler \& M. A. Gernsbacher (Eds.), Handbook of psycholinguistics (pp. 765-800). London: Elsevier. http://dx.doi.org/10.1016/B978-012369374-7/50020-1

McManus, C. (2002). Right hand, left hand: The origins of asymmetry in brains, bodies, atoms and cultures. London: Weindenfeld \& Nicolson.

Mishkin, M., \& Forgays, D. G. (1952). Word recognition as a function of retinal locus. Journal of Experimental Psychology, 43, 43-48. http://dx.doi.org/10.1037/h0061361

Pointer, J. S. (2012). Sighting versus sensory ocular dominance. Journal of Optometry, 5(2), 52-55. http://dx.doi.org/10.1016/j.optom.2012.03.001

Porac, C., \& Coren, S. (1975). Is eye dominance a part of generalized laterality? Perceptual Motor Skills, 40(3), 
Shakouri, N., \& Maftoon, P.

763-769. http://dx.doi.org/10.2466/pms.1975.40.3.763

Rice, M. L., Leske, D. A., Smestad, C. E., \& Holmes, J. M. (2008). Results of ocular dominance testing depend on assessment method. Journal of American Association for Pediatric Ophthalmology and Strabismus, 12(4), 365-369. http://dx.doi.org/10.1016/j.jaapos.2008.01.017

Saunders, A. D., \& Vawdrey, C. (2002). Merging brain research with educational learning principles. Business Education Forum, 1, 44-46.

Schmidt, R. W. (1995). Consciousness and foreign language learning: A tutorial on the role of attention and awareness in learning. In R. W. Schmidt (Ed.), Attention and awareness in foreign language learning (pp. 1-63). Honolulu: University of Hawai'i.

Slegers, B. (1997). Brain development and its relationship to early childhood education. Paper presented at EDEL seminar in elementary education, Long Beach, CA.

Sperry, R. (1981). Some effects of disconnecting the cerebral hemispheres. Retrieved from http://people.uncw.edu/puente/sperry/sperrypapers/80s

Viskari, K. (2005). Foreign language learning disabilities: Theoretical and practical tools for English teachers in Finnish upper secondary schools (Unpublished master's thesis). Retrieved from https://jyx.jyu.fi/dspace/bitstream/handle/123456789/7414/urn_nbn_fi_jyu-2005164.pdf?sequence=1

Woodhouse, R. (2009). A changing view of eye dominance (Unpublished doctoral thesis). Retrieved from http://orca.cf.ac.uk/55827/1/U584362.pdf

Zeinaly, A., \& Ashayeri, H. (2000). Preliminary study of the relationship of look direction with specific function of the cerebral hemispheres. Psychological Research, 5(3), 26-36. 